\title{
Influence of Fog-Haze on Dew Condensation in Urban Areas
}

\author{
Yingying XU, Hui ZHU, Yuepeng PAN, Jing XIE
}

\begin{abstract}
In recent years, fog-haze weather has frequently occurred in urban ecosystem, with accompanied dew condensation in the surface layer. Dew formation plays an important role in air purification, which takes fine aerosols in the atmosphere as the condensation nuclei. However, the influence of fog-haze on dew condensation remains unclear. Thus, this study aims to evaluate the influences of fog-haze days on the frequency, intensity, and duration of dew condensation, to reveal the factors relevant to dew condensation during weather pollution, and to improve the air quality in fog-haze days. The monitor-based direct weighing method was employed in this study to observe the vapour condensation in urban greenbelt under fog-haze and normal weather conditions during the frost-free season (April-October 2017) in Changchun, China. The differences in dew condensation intensity and frequency were discriminated under different weather conditions. Then, the influences of fog-haze days on the vapour condensation were analyzed by monitoring the velocity and duration of dew condensation in polluted weather. Finally, a program for improving air quality was proposed based on the analysis of major meteorological factors that affect the dew condensation during the fog-haze days. Results show that the dew condensation velocity decreases significantly $(P<0.01)$ from $0.0067 \mathrm{~mm} / \mathrm{h}$ in normal weather to $0.0026 \mathrm{~mm} / \mathrm{h}$ in a fog-haze day, whereas the condensation duration is prolonged. The dew condensation intensities are $0.064,0.045$, and $0.051 \mathrm{~mm} / \mathrm{d}$ under fog, haze, and normal weather conditions, respectively, and the fog-haze weather has no significant effect on the frequency or intensity of dew condensation $(P>0.05)$. The particulate matter concentration, wind speed, air pressure, relative humidity, and solar radiation are the main factors that affect the vapour transport during the fog-haze days. Artificial increase of surface layer vapours can promote the particulates to absorb vapours fully and settle to the ground in the form of dew, thereby reducing the particulate matter concentration within the scope of human activities. The present study supplements the eigenvalues for dew condensation in urban areas during special pollution periods and reveals the influence of fog-haze on the night time vapour condensation in urban areas. Findings of this study provide theoretical basis for further developing the programs for controlling fog-haze weather and improving urban air quality.
\end{abstract}

Keywords: condensation intensity; condensation period; dew; fog-haze day; particle

\section{INTRODUCTION}

Dew and fog-haze are meteorological phenomena. Fog-haze is a severe weather that causes disasters, which China is currently facing, and occurs frequently in cities. Given the large-scale hardening of surface layer and heat island effect, cities are also the "landscape unit" where dew condensation occurs frequently not only at high frequency but also in large dew amount $[1,2]$. Dew and fog-haze are similar in formation time and meteorological conditions. Approximately $80 \%$ of the fog-haze weather occurs in autumn and winter, and the dew amount peaks in autumn. Moreover, dew and fog-haze easily form under the meteorological conditions of small winds and high relative atmospheric humidity. The difference in formation between the two lies in the relative atmospheric humidity. Fog-haze easily forms when the relative atmospheric humidity is between $75 \%$ and $90 \%$, whereas vapours form foggy dew on the surface when the relative humidity is above $90 \%$ [3]. The formations of fog-haze and dew are mutually transformable with the changing relative humidity [4]. Cities are a place where the people gather. Near-surface airborne particles (e.g. inhalable particles $P \mathrm{M}_{10}$ and fine particulates $P \mathrm{M}_{2.5}$ ) have a direct and strong effect on human health [5]. Particles act as condensation nuclei that absorb vapours in the atmosphere, which undergo adsorption, ingestion, homogeneous or heterogeneous chemical transformations, moisture absorption, bonding, and agglomeration processes to form dew, meanwhile, the condensation phase is a natural purification process of the near-surface particles (e.g., $P \mathrm{M}_{2.5}$ and $P \mathrm{M}_{10}$ ) and gas pollutants (e.g., $\mathrm{NH}_{3}, \mathrm{SO}_{2}$, and $\left.\mathrm{NO}_{x}\right)[6 \div 8]$. Therefore, the intensity, frequency, and influencing factors of dew condensation have become the research focus at home and abroad.

Dew has a prominent scavenging effect on atmospheric particulates, meanwhile, air quality deteriorates rapidly, and aerosol load and relative humidity increase significantly during fog-haze days [9, 10]. In recent years, research on fog-haze weather process, dew amount in urban areas, and water quality has been gaining increasing attention among scholars $[11 \div$ 13], especially the transformation of particulates during fog-haze days, which is a recent hot topic. Lang et al. [14] and Zhang et al. [15] found that vapours provided a heterogeneous transformation carrier for gas pollutants during the moisture absorption and growth of particulates. They also found that vapour was the key factor in transforming the polluted gases into secondary pollution and reducing visibility during the fog-haze process, which was the reactor for liquid-phase oxidation. However, they failed to monitor the frequency and intensity of vapour condensation in the surface layer during the fog-haze process, thereby limiting the study on the matter transformation mechanisms in processes such as fog-haze particulate deposition and dissipation. Gałek et al. [2] and Beysens et al. [16] observed surface-layer vapour condensation in Wroclaw, Poland and Paris, respectively, and revealed markedly higher daily dew amount in the suburban area $(0.18 \div 0.42 \mathrm{~mm})$ than the urban area $(0.09$ $\div 0.22 \mathrm{~mm}$ ) for Wroclaw and significantly lower annual dew amount in downtown area $(3.5 \mathrm{~mm})$ than the suburban area $(17 \mathrm{~mm})$ for Paris. Their studies utilized dew under normal weather conditions as an input for the water balance of wet deposition; however, they did not consider the observation data of dew condensation during fog-haze days. Xu et al. [17] analyzed the dew water quality during fog-haze days and demonstrated that the $P \mathrm{M}_{2.5}$ and $P \mathrm{M}_{10}$ concentrations from dew deposition during the fog-haze days were $1.79 \div 2.48$ times higher than those under normal weather conditions. They indicated that the total dissolved solids reached 271.36 $\mathrm{mg} / \mathrm{l}$ [17] and that the dew condensation could remove $21.5 \%$ and $13.7 \%$ of $P \mathrm{M}_{2.5}$ in the surface layer under the 
normal and fog-haze weather conditions, respectively [18]. Despite the revelation that dew formation was conducive to the particulate deposition in the surface layer during fog-haze days, $\mathrm{Xu}$ et al. only focused on the analysis of dew water quality without investigating the velocity or influencing factors of dew deposition, thereby limiting the understanding of the particulate deposition during fog-haze days. This limitation is not conducive to the formulation of atmospheric environment management programs for fog-haze days. Hence, the monitoring and research of dew condensation during fog-haze days are highly necessary.

Moreover, Xu et al. [19] revealed that the annual dew amount in their study area could reach $22.98 \mathrm{~mm}$. Clearly, the dew in the urban ecosystem was not only large in amount but was also beneficial to the removal of $P \mathrm{M}_{10}$, $P \mathrm{M}_{2.5}$, and other harmful particulates within the scope of human activities $(0 \div 3 \mathrm{~m}$ scale $)$. However, the influence of fog-haze on the dew condensation remains unclear. Fog-haze weather provides sufficient vapour conditions and condensation nuclei for dew condensation, and whether it promotes or inhibits dew condensation warrants further discussion. Moreover, fog-haze days are mostly under calm wind and temperature inversion conditions with high relative humidity, where the thick inversion temperature layer weakens the solar radiation near the surface $[20,21]$. All major meteorological factors that may affect dew condensation undergo considerable changes during fog-haze days. Therefore, dew condensation and its influencing factors during the foghaze days in urban areas warrant further research, and the management of atmospheric environment on the basis of such research must be strengthened. In the present work, the dew intensity, atmospheric particulate matter concentration, and relative meteorological factors under fog-haze and normal weather conditions in Changchun's greenbelt were considered research indices based on the preliminary monitoring of dew in the study area. This study aims to explore further the influence of fog-haze on the intensity, velocity, and duration of dew condensation, to determine the main factors that affect the dew condensation in urban areas during fog-haze days, and to propose concrete measures for the improvement of the atmospheric environment during fog-haze days.

The remainder of this study is organized as follows. Section 2 describes the classification criteria between foghaze and normal weather, as well as the location and method of dew monitoring. Section 3 discusses the intensity and duration of dew condensation under different meteorological conditions by dew monitoring and the influences of fog-haze on dew condensation. Moreover, the main factors that affect the surface-layer vapour condensation are analyzed, and the measures for improving fog-haze environmental quality in urban areas are proposed based on the relevant results. Finally, Section 4 concludes this study and presents relevant conclusions.

\section{MATERIALS AND METHODS}

\subsection{Experimental Location and Time}

Changchun is located in the hinterland of Northeast China $\left(43^{\circ} 05^{\prime} \mathrm{N}-45^{\circ} 15^{\prime} \mathrm{N} ; 1^{\circ} 4^{\circ} 18^{\prime} \mathrm{E}-127^{\circ} 02^{\prime} \mathrm{E}\right)$. It has a continental monsoon climate with an annual average temperature of $4.8^{\circ} \mathrm{C}$ and annual average precipitation of $522 \div 615 \mathrm{~mm}$. The industrial and commercial development has been rapid in Changchun, where the foghaze weather is characterized by long duration and high frequency. The climatic characteristics of the experimental site are suitable for dew condensation with annual dew days of over 130 days and annual dewfall of $23 \div 35 \mathrm{~mm}$ [22]. Observations were conducted daily over the plant growth period (early April-late October) in 2017. The experimental observation site was set up at Jilin Jianzhu University in the southeast of Changchun. The university is situated in the heart of downtown and suburbs, which is representative. The campus green zone was selected as the experimental greenbelt, where all the plant types were common shrubs or small arbors for urban greening in Northeast China, including Buxus sinica var. parvifolia $M$. Cheng, Berberis thunbergii var. atropurpurea Chenault, and Ligustrum quihoui Carr. Observing frame was installed in the greenbelt for dew condensation observation on a daily basis.

\subsection{Experimental Process}

Poplar wooden sticks were used as dew monitors in the urban greenbelt. The sticks were solid polished cuboid sticks with a size of $20 \times 4 \times 4 \mathrm{~cm}$. The solid wooden sticks were placed in sealable clean plastic cases, weighed separately with a balance $(0.001 \mathrm{~g}$ precision), and recorded. At half an hour after sunset, all the sticks were sent to various test points, which were then taken out and placed on the plant canopies. At half an hour before sunrise, the wooden sticks were removed, placed in the clean plastic cases correspondingly, weighed separately with a balance $(0.001 \mathrm{~g}$ precision), and recorded. Distinguishing between night-time dew condensation and rainfall during dew days was difficult, thus, the dew amount of the day would be 0 if precipitation days occurred after sunset and before sunrise [19]. Through this method, the frequency and intensity of dew condensation in the urban ecosystem could be monitored daily.

To determine the influence of fog-haze on the dew condensation period, the vapour condensation velocity tests were conducted by selecting normal and fog-haze weathers in July 2017. At $30 \mathrm{~min}$ after sunset, several weighed monitors were placed separately on the observing frame. From the sunset (about 18:00) until the early morning of the next day, one monitor was removed per hour for weighing. Through this method, the amount of dew condensed for each hour, that is, the condensation velocity, could be calculated, thereby establishing the start and end time for vapour condensation.

As a natural phenomenon under the influence of microclimate, the conditions of dew condensation are weakly correlated with the variation of remote meteorological factors. Therefore, meteorological indices, such as relative humidity $(R H, \%)$, dew point temperature $\left(T_{d},{ }^{\circ} \mathrm{C}\right)$, air temperature $\left(T_{a},{ }^{\circ} \mathrm{C}\right)$, radiation $\left(R_{n}, \mathrm{MJ} / \mathrm{m}^{2}\right)$, wind speed $\left(V_{\text {night }}, \mathrm{m} / \mathrm{s}\right)$ at $1 \mathrm{~m}$ from the surface layer, precipitation $(\mathrm{mm})$, wind direction, and vapour pressure $(P, \mathrm{hpa})$ were measured at the test points. All the indices were recorded at an interval of one hour. During data 
processing, radiation was the sum of daytime radiation, whereas other factors were the average values for the condensation period. The hourly air quality index (AQI) and atmospheric particulate matter concentrations (i.e., $P \mathrm{M}_{10}$ and $P \mathrm{M}_{2.5}$ ) were monitored in real time at the monitoring points using an aerosol monitor (DRX 8533EP, USA), whereas the remaining meteorological indices were monitored in real time at the test points using a weather station (MILOS 520, Finland).
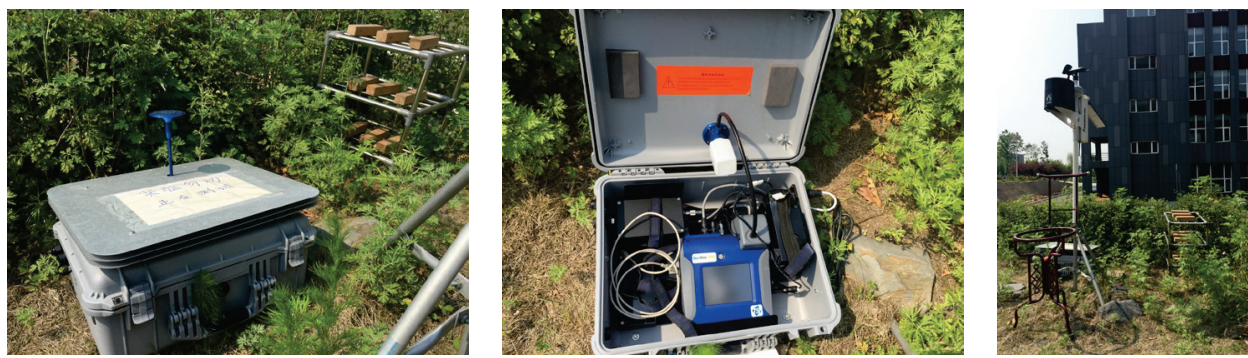

Figure 1 Experimental observation equipment (Left and middle: aerosol monitors; Right: weather station)

\subsection{Dew Intensity Calculation and Statistics}

The single-day dew intensity at the test points is calculated as follows:

$I=\frac{10 \cdot\left(W_{r}-W_{s}\right)}{S}$

where 10 is the conversion factor; $I$ denotes the single-day dew intensity at the test points $(\mathrm{mm}) ; W_{s}$ and $W_{r}$ represent the weight of each monitor at the start and end of dew condensation, respectively ( $\mathrm{g}$ ); and $S$ denotes the effective surface area of dew monitoring $\left(\mathrm{cm}^{2}\right)$. The normality test, significant differences, and correlation analysis of the experimental data were performed using SPSS 16.0 software.

\subsection{Classification Criteria between Fog-Haze and Normal Weathers}

According to the fog-haze weather criteria promulgated by the China Meteorological Administration, fog-haze and normal weathers can be distinguished by the monitoring values of visibility and relative humidity. The weather is fog-haze when visibility is below $10 \mathrm{~km}$, of which those with a relative humidity of $\geq 90 \%$ are fog days and $<90 \%$ are haze days, whereas the weather is normal when the visibility is above $10 \mathrm{~km}$. On this basis, the dew days totalled 137 days in 2017, including 11 fog days, 11 haze days, and 115 normal days.

The meteorological characteristics and particulate matter concentrations in the fog-haze and normal weathers during the sampling period are listed in Tab. 1. The meteorological characteristics of atmospheric static stability resulted in the low visibility and high particulate matter concentration during the fog-haze weather. After data analysis, no significant differences were found in the relative humidity or wind speed between the fog-haze and normal weathers $(P>0.05)$, and the $P \mathrm{M}_{10}$ and $P \mathrm{M}_{2.5}$ were significantly higher in the fog-haze weather than in the normal weather $(P<0.01)$. Temperature was the most significant difference between the two meteorological characteristics, because the straw burning in the periphery of Changchun and the coal combustion for centralized heating were the primary causes of fog-haze weather. Therefore, the fog-haze weather in the experimental area occurred mostly during autumn and winter, during which the temperature was lower than the normal weather.

Table 1 Average values for the condensation period of meteorological factors and particulate matter concentrations in fog-haze and normal days

\begin{tabular}{|l|c|c|}
\hline & Normal & Fog and Haze \\
\hline AQI & 71.89 & 136.74 \\
\hline$P M_{2.5}\left(\mu \mathrm{g} / \mathrm{cm}^{3}\right)$ & 29.04 & 99.34 \\
\hline$P M_{10}\left(\mu \mathrm{g} / \mathrm{cm}^{3}\right)$ & 66.97 & 141.81 \\
\hline$R H(\%)$ & 67.89 & 72.78 \\
\hline Wind speed $(\mathrm{m} / \mathrm{s})$ & 0.50 & 0.56 \\
\hline Visibility $(\mathrm{km})$ & 14.63 & 6.59 \\
\hline Pressure $(\mathrm{kPa})$ & 98.34 & 98.72 \\
\hline Dew point $\left({ }^{\circ} \mathrm{C}\right)$ & 9.07 & 7.15 \\
\hline Temperature $\left({ }^{\circ} \mathrm{C}\right)$ & 15.69 & 12.31 \\
\hline
\end{tabular}

\section{RESULTS AND DISCUSSION}

\subsection{Influences of Fog-Haze on Frequency and Intensity of Dew Condensation}

The influence of fog-haze weather on the frequency and intensity of dew condensation in the urban ecosystem is discussed in this section based on the method for dew day observation mentioned in Section 2.2 and Eq. (1) for dew intensity mentioned in Section 2.3. Fig. 2 shows that fog or haze weather had no effect on the frequency of vapour condensation on the underlying surface. Dew condensation phenomena occurred under fog or haze weather conditions with condensation frequency accounting for $64.02 \%$ of the experimental period. The monitoring results revealed that dew condensation was consistently present during fog-haze weather; however, the meteorological feature of fog-haze did not necessarily occur in the presence of dew condensation. No significant differences were found in the daily dew condensation intensity among the fog weather $(0.064 \mathrm{~mm} / \mathrm{d})$, haze weather, $(0.045 \mathrm{~mm} / \mathrm{d})$ and normal weather $(0.051 \mathrm{~mm} / \mathrm{d}$; $P>0.05)$. Richards $[23,24]$ found that the dew amounts in the urban grasslands and suburban areas of Vancouver were $0.11 \div 0.13 \mathrm{~mm} / \mathrm{d}$ per night and that the average daily dew amounts in the urban area were 0.07-0.09 $\mathrm{mm} / \mathrm{d}$, which were slightly higher compared with the present study area. This finding might be attributable to Vancouver's temperate maritime climate, where the relative humidity was higher and the vapours were easier to condense during night-time. The intensity of dew condensation in the present study area was higher than the 
dew amount of the Guangzhou Forest Park $(0.034 \mathrm{~mm} / \mathrm{d})$, as well as the commercial areas $(0.013 \mathrm{~mm} / \mathrm{d})$, residential areas $(0.009 \mathrm{~mm} / \mathrm{d})$, and industrial areas $(0.022 \mathrm{~mm}) / \mathrm{d})$ with large human disturbance [25]. This phenomenon was mainly due to the larger diurnal temperature variation and smaller wind speed in the experimental area than Guangzhou, which was prone to heavy dew condensation.

Despite the easy formation of fog-haze weather in the "static stability" weather condition, the atmosphere was rather stable, which easily resulted in a low inversion temperature layer and difficult dispersion of pollutants. However, according to the monitoring results (Fig. 2), the vapours in the surface layer could still be transferred to the underlying surface with accompanying deposition of particulates. Moreover, $P M_{10}$ and $P M_{2.5}$ in dew were significantly higher during fog-haze days than normal days $(P<0.05)$, which were about twice those under the normal weather; furthermore, the contents of conventional ions in dew during the fog-haze days were $3 \div 9$ times those under the normal weather, almost all water-soluble ions in dew increased in the fog-haze weather, and $\mathrm{Na}^{+}$, $\mathrm{Mg}^{2+}$, and $\mathrm{Ca}^{2+}$ from the crustal source increased by 3.01 $\div 3.67$ times, the $\mathrm{NH}_{4}{ }^{+}, \mathrm{SO}_{4}{ }^{2-}$, and $\mathrm{NO}_{3}{ }^{-}$derived from the secondary species of acidic gases that were emitted from anthropogenic sources all increased by more than 5 times, especially the growth from biomass burning, which was the highest, reaching 9.32 times [17]. These results and the condensation intensity of dew under the fog-haze weather revealed that despite the slow condensation of vapours in the surface layer under fog-haze weather, spontaneous deposition of aerosols and other substances consistently occurred. In summary, fog-haze days did not affect the frequency and intensity of dew condensation, and dew remained an important approach for the removal of surface-layer pollutants whether under normal or foghaze weather conditions.

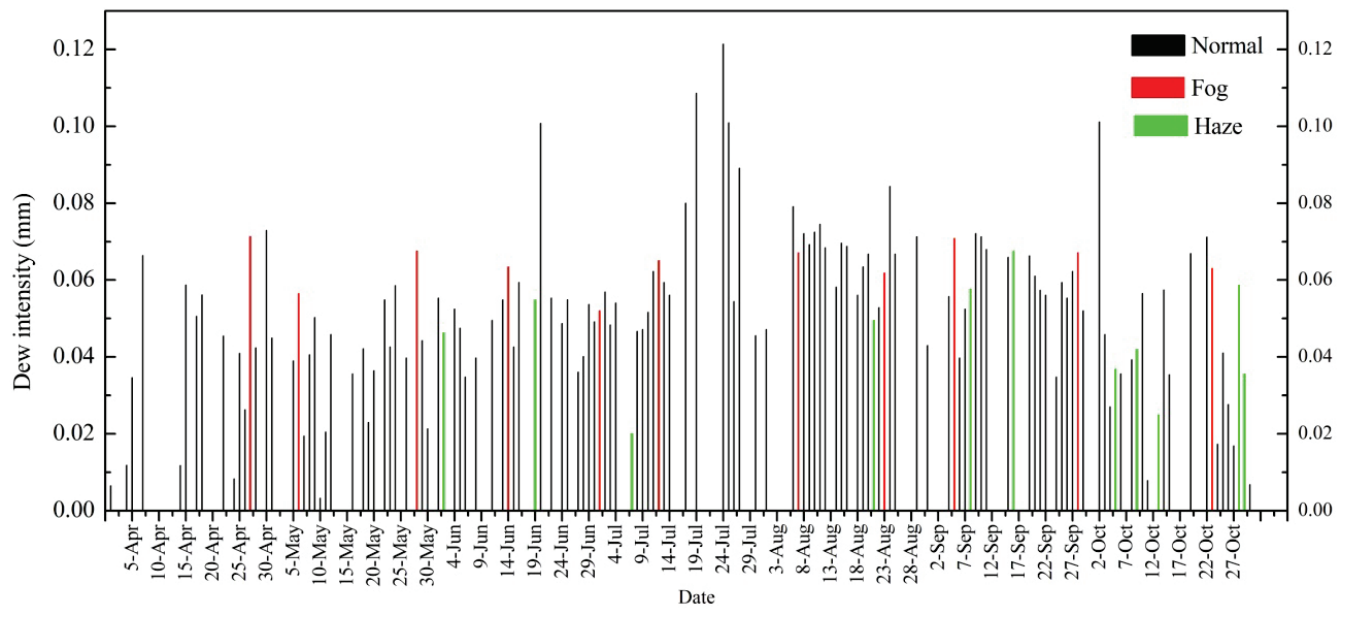

Figure 2 Dew intensity variations on normal, fog, and haze days in 2017 in Changchun City

\subsection{Influence of Fog-Haze on the Velocity and Duration of Dew Condensation}

This section discusses the influence of fog-haze on the velocity and duration of dew condensation in the urban ecosystem based on the methods for monitoring dew condensation velocity and duration mentioned in Section 2.2. The normal dew condensation time is generally half an hour after the local sunset until half an hour before sunrise on the next day [26]. However, the experimental results revealed that the dew condensation was unrelated to the time of sunrise or sunset under the fog-haze weather condition and that the fog-haze weather condition did not conform to the emergence characteristics of intrinsic dew condensation period. Instead, the dew condensation was consistently present along with the occurrence of fog-haze. Taking the twotime continuous diurnal observations in July 2017 as an example, the sunrise time in Changchun was about 6:00 in July, whereas the sunset time was about 19:00. Days July 3-4 were the representatives of normal weather, whereas July 12-13 were the representatives of fog-haze weather. Figs. 3 and 4 show that the vapour condensation on July 3-4 accorded with the basic law of the dew condensation period. On clear nights, the relative humidity satisfied the condensation conditions when the temperature declined to the dew point temperature at half an hour after sunset and the vapours in the underlying surface began to condense by the action of breeze. On mornings of next days, the vapours in the surface layer underwent evaporation instead of condensation at half an hour before sunrise with rising temperature and declining relative humidity.

On July 12 , the visibility was below $10 \mathrm{~km}$ and the relative humidity $(R H)$ was less than $90 \%$ since 18:00 in the evening and the meteorological features of haze began to appear. At that time, vapours began to condense on the underlying surface. The condensation was relatively slow from 19:00 to 23:00, which accelerated from 00:00 to 6:00 of the next morning. After sunrise, despite the gradual increase in temperature and the decrease in relative humidity, the downward migration of vapours was still observed at the underlying surface under the haze condition, however, its velocity declined. At around 11:00 on July 13, the visibility became higher than $10 \mathrm{~km}$ with the increasing wind speed and haze was eliminated. At that time, the vapours were lacked of condensation conditions and the dew amount no longer changed. Comparison of the two experiments indicated that the average velocities for dew condensation were 0.0067 $\mathrm{mm} / \mathrm{h}$ and $0.0026 \mathrm{~mm} / \mathrm{h}$ and that the dew condensation velocity was significantly higher in normal weather than in fog-haze weather over the same condensation period $(P$ $<$ 0.01). However, during the haze days, the meteorological conditions in the surface layer were 
"warm and wet inversion", which were favourable for delaying the condensation time of vapours. On July 1213 , the daily dew condensation time was as long as $16 \mathrm{~h}$, thus, no significant difference in the dew intensity was observed between normal and fog-haze weathers. Clearly, the fog-haze days slowed down the dew condensation and prolonged its duration.

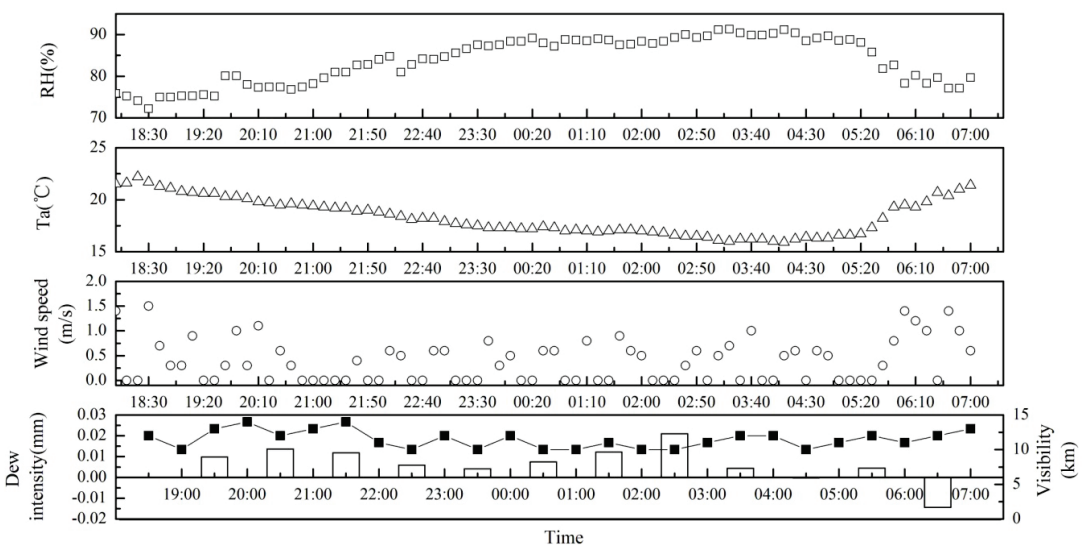

Figure 3 Hourly condensation velocity and hourly meteorological factors on July 3-4, 2017

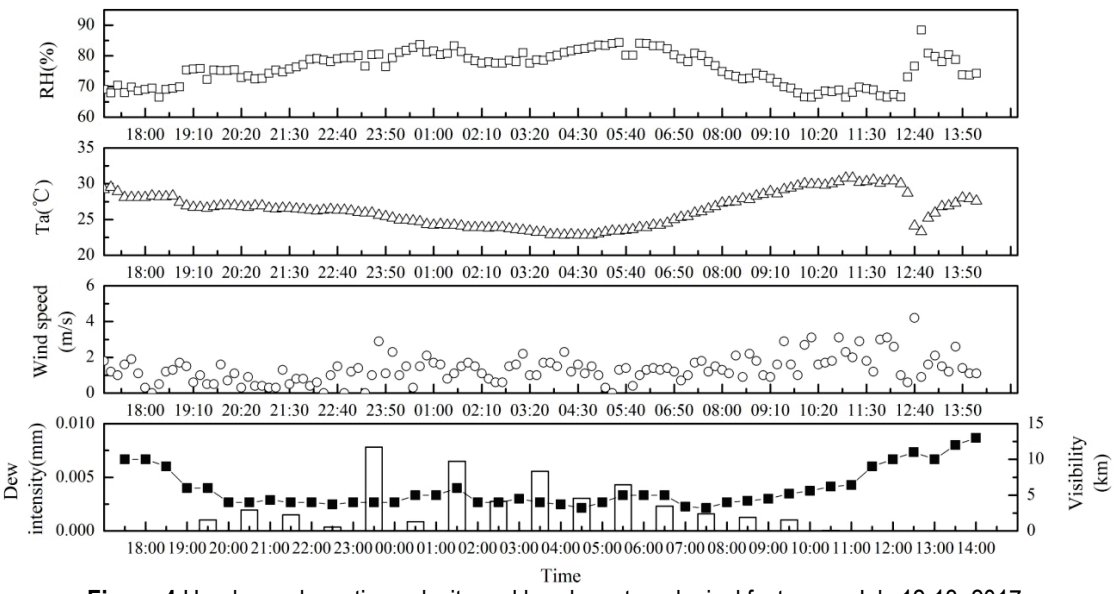

Figure 4 Hourly condensation velocity and hourly meteorological factors on July 12-13, 2017

\subsection{Factors Affecting Dew Condensation during Fog-Haze Days}

This section proposes the measures for improving the air quality of the surface layer under the fog-haze weather condition based on the analysis of the major factors of dew condensation during the fog-haze days according to the monitoring methods of meteorological factors and the correlation analysis method mentioned in Sections 2.2 and 2.3. The conditions for dew formation were rather complex, and the formation process was constrained mainly by the different local meteorological factors in various regions. The dew intensity and night-time meteorological data of Changchun during the fog-haze days in 2017 were used for the correlation analysis. Tab. 2 indicates that the dew intensity $(I)$ was positively correlated with the relative humidity $(R H)$, temperature
$\left(T_{a}\right)$, and solar radiation $\left(R_{n} ; n=22, P<0.01\right)$ in the urban greenbelt; whereas it was negatively correlated with the $P M_{2.5}, P M_{10}$ nighttime wind speed $\left(V_{\text {night }}\right)$, pressure $(P)$, and AQI $(n=22, P<0.01)$. Under normal weather conditions, the dew condensation intensity was only positively correlated with the relative humidity and dew point temperature, whereas it was negatively correlated with the wind speed $[27 \div 29]$. Clearly, the factors that affect vapour condensation in the underlying surface were more complex during the fog-haze days than normal days, which included the particulate matter concentration in the surface layer, solar radiation, and pressure aside from the conventional dew condensation influencing factors (i.e., relative humidity, dew point temperature, and wind speed).

Table 2 Correlation coefficients between dew intensity and meteorological factors in the greenbelt

\begin{tabular}{|c|c|c|c|c|c|c|c|c|c|c|}
\hline & $P M_{2.5}$ & $P M_{10}$ & $R H$ & $T_{a}$ & $V_{\text {night }}$ & Wind direction & $R_{n}$ & $P$ & Rainfall & AQI \\
\hline Dew intensity & $-0.306^{* *}$ & $-0.348^{* *}$ & $0.766^{* *}$ & $0.467^{* *}$ & $-0.489^{* *}$ & 0.015 & $0.356^{* *}$ & $-0.242^{* *}$ & 0.109 & $-0.316^{* *}$ \\
\hline
\end{tabular}

** Correlation is significant at the 0.01 level (2-tailed)

$P M_{2.5}$ and other particulates were the main atmospheric pollutants under the fog-haze meteorological condition, which also provided the condensation nuclei for the dew formation. During the fog-haze days, the relative humidity markedly increased and the water molecules in the atmosphere exhibited the functions of 
absorption, bonding, and particulate deposition. When the atmosphere contained particulates and water molecules, the condensed particles grew continuously and dropped smoothly to the ground under the influence of gravity and other conditions after growing to a certain extent to form dew, which effectively adsorbed the particles suspended in the atmosphere and eventually descended to the ground. Thus, presumably, when the total particulate matter concentration in the atmosphere increased under the fog-haze weather condition, the dew amount should increase if sufficient vapours existed. However, $P M_{2.5}$ and $P M_{10}$ had significant negative correlations with the AQI and dew condensation intensity $(n=22, P<0.01$; Tab. 2$)$. Large dew deposition could be observed under good air quality condition, and the vapour condensing capability weakened under the fog-haze weather condition. This phenomenon may be due to the sharp increase in the content of pollutants from combustion of farmland biomass, ground dust, coal combustion, industrial oil burning, and secondary particles in the fog-haze atmosphere, which intensified the heterogeneous reactions on the surface of particulates at high vapour content [30]. For example, the heterogeneous reaction between $\mathrm{NO}_{2}$ and water molecules on the wet surfaces produced HONO gas (Formula 2), which was highly likely to occur on the aerosol surfaces (including cloud droplets, fog drops, and airborne particulates) [31]. Some of the HONO in the product was released from the ground surface and returned to the atmosphere, whereas $\mathrm{HNO}_{3}$ remained on the reaction surface and deposited after the liquid water adsorption at the interface.

$$
2 \mathrm{NO}_{2}+\mathrm{H}_{2} \mathrm{O}_{\mathrm{ads}} \rightarrow \mathrm{HONO}+\mathrm{HNO}_{3}
$$

Therefore, the particulates underwent a conversion from gases to aerosols and then to droplets under the foghaze weather condition. Moreover, the atmospheric contents of fine particles, such as $\mathrm{SO}_{4}{ }^{2-}, \mathrm{NO}_{3}{ }^{-}$, and $\mathrm{Cl}^{-}$ increased [32, 33]. Aerosol particles experienced heterogeneous reactions through moisture absorption. During the conversion from aerosols to droplets, condensation would be difficult if vapours were insufficient and the suspended state would result in a decrease in the visibility of surface layer through the atmosphere. Fig. 4 shows that the condensation did not remarkably improve the visibility of underlying surface in the fog-haze days. Although the condensation could remove the surface-layer particles, most of the particles (especially fine particles) absorbed moisture in the atmosphere and the particle size increased rapidly. The vapours contained by particles failed to reach the maximum limit and were unable to promote the excess moisture to bind particles to form water droplets. That is, a high relative humidity could pose a certain effect on the atmospheric visibility by affecting the moisture content of particulates [34]. If the relative humidity in the air continued to increase beyond the hygroscopic threshold of fine aerosols, then the potential dew could easily be converted into effective dew.

To sum up, the influences of fog-haze days on dew were rather complex, which was affected jointly by conditions, such as particulate type and relative humidity. At high air humidity under fog-haze weather condition, particles were easily deposited in the surface layer. Therefore, the deposition of fine particles could be accelerated by increasing the water molecules in the atmosphere by spraying water droplets in the surface layer during the fog-haze days. During condensation, artificial vapours migrated upward with the air flow and spread disorderly to increase the atmospheric density of space. The moisture underwent internal and external latent heat exchange in random chaos, continuous transformation of matter and energy, and changes in potential and kinetic energies. Through fluctuations, the moisture in the air saturated, condensed, and phase-exchanged at the dew point and bonded to the condensation nuclei, thereby breaking the hygroscopic threshold to produce dew. The water molecules transformed from the turbulent motion of invisible micro-vapour water to the state of macro-entity dew particles. During condensation, the vapours absorbed, neutralized, and transformed the acidic or alkaline characteristic of particles in the atmosphere, slowed down the atmospheric pollution, and effectively purified the atmosphere. Under the fog-haze weather conditions, the artificial transmission of vapours into the air was beneficial to the deposition of particulates, which was an effective means of purifying air and controlling air pollution.

\section{CONCLUSION}

To determine the influence of fog-haze weather on the intensity, frequency, velocity, and duration of surfacelayer dew condensation in urban ecosystems and reveal the factors that affect the water cycle in the surface layer under fog-haze weather condition. The differences in the surface-layer vapour condensation between the two weather conditions were discriminated in this study. The main factors that affect dew condensation during fog-haze days were analyzed based on monitoring the dew condensation under the fog-haze and normal weather conditions in the urban greenbelt (Changchun, China). Furthermore, measures for improving the air quality in the surface layer were proposed. The conclusions drawn are as follows.

(1) Fog-haze days do not have obvious effect on the frequency or intensity of vapour condensation in the surface layer. Dew condensation is present during the foghaze days, and the daily dew condensation intensities are $0.064,0.045$, and $0.051 \mathrm{~mm} / \mathrm{d}$ for the fog, haze, and normal weathers, respectively, without showing significant differences $(P>0.05)$.

(2) Time nodes of dew condensation change markedly in the fog-haze days. Dew condensation is unconstrained by the sunrise and sunset conditions and is present throughout the fog-haze days. Despite the significant reduction in condensation velocity due to the changes in the surface meteorological conditions during the fog-haze days $(P<0.01)$, the fog-haze delays the vapour condensation time. Thus, no significant difference is found in the dew intensity between the normal and foghaze weather conditions.

(3) Factors that affect the surface-layer vapour condensation during the fog-haze process are complex. The dew intensity $(I)$ is positively correlated with the relative humidity $(R H)$, temperature $\left(T_{a}\right)$, and solar 
radiation $\left(R_{n} ; n=22, P<0.01\right)$; whereas it is negatively correlated with $P M_{2.5}, P M_{10}$ night-time wind speed $\left(V_{\text {night }}\right)$, pressure $(P)$, and AQI $(n=22, P<0.01)$.

(4) During fog-haze, the vapour content in the atmosphere can be increased by artificial watering and other measures. After the vapour absorbing capacity of particulates reaches supersaturation, they settle on the surface to complete the surface migration of atmospheric vapours and particulates, thereby improving visibility and purifying the air.

In conclusion, the frequency, intensity, velocity, and duration of vapour condensation within the scope of human activities under heavily polluted weather conditions are ascertained in this study through the analysis of the influence of urban fog-haze on vapour condensation. The moisture absorption by the particulates in the underlying surface is also investigated, which provides the theoretical basis for the development of programs for controlling fog-haze and improving urban air quality. Dew in the urban ecosystem is an effective channel to remove particulates and gas pollutants in the surface-layer atmosphere. However, as an intermediate product that alternately forms and dissipates day and night, whether dew evaporation releases most of the pollutants dissolved or adsorbed in it remains unclear. In future works, the matter of circulation in dew evaporation warrants further understanding.

\section{ACKNOWLEDGEMENTS}

This work was supported by the Special S\&T Project on Treatment and Control of Water Pollution (project no. 2010ZX07320-003-004) and Technology Program of Jilin Province (project no. 201705200827JH) and the Youth Innovation Promotion Association CAS (No. 2017274). The authors gratefully acknowledge financial support from China Scholarship Council (no. 201708220027) for 1 year study at the University of Toronto.

\section{REFERENCES}

[1] Meunier, D. \& Beysens, D. (2016). Dew, fog, drizzle and rain water in Baku (Azerbaijan). Atmospheric Research, 178-179, 65-72. https://doi.org/10.1016/j.atmosres.2016.03.014

[2] Gałek, G., Sobik, M., Błaśa, M., Polkowska, Ż., CichałaKamrowska, K., \& Wałaszek, K. (2015). Dew and hoarfrost frequency, formation efficiency and chemistry in Wroclaw, Poland. Atmospheric Research, 151(1), 120-129. https://doi.org/10.1016/j.atmosres.2014.05.006

[3] Huang, L. K., Yuan, C. S., Wang, G. Z., \& Wang, K. (2011). Chemical characteristics and source apportionment of $\mathrm{PM}_{10}$ during a brown haze episode in Harbin, China. Particuology, 9(1), 32-38. https://doi.org/10.1016/j.partic.2010.07.022

[4] Gultepe, I. (2012). Fog and dew observations and modeling: Introduction. Pure and Applied Geophysics, 169(5-6), 765-766. https://doi.org/10.1007/s00024-012-0471-y

[5] Tang, G. Q., Zhao, P. S., Wang, Y. H., Gao, W. K., Cheng, M. T., Xin, J. Y., Li, X., \& Wang, Y. S. (2017). Mortality and air pollution in Beijing: The long-term relationship. Atmospheric Environment, 150, 238-243. https://doi.org/10.1016/j.atmosenv.2016.11.045

[6] Muskała, P., Sobik, M., Błaś, M., Polkowska, Ż., \& Bokwa, A. (2015). Pollutant deposition via dew in urban and rural environment, Cracow, Poland. Atmospheric Research, 151, 110-119. https://doi.org/10.1016/j.atmosres.2014.05.028

[7] Rubio, M. A., Lissi, E., Herrera, N., Pérez, V., \& Fuentes, N. (2012). Phenol and nitrophenols in the air and dew waters of Santiago de Chile. Chemosphere, 86(10), 10351039. https://doi.org/10.1016/j.chemosphere.2011.11.046

[8] Polkowska, Ż., Błaś, M., Klimaszewska, K., Sobik, M., Małek, S., \& Namieśnik, J. (2008). Chemical characterization of dew water collected in different geographic regions of Poland. Sensors, 8(6), 4006-4032. https://doi.org/10.3390/s8064006

[9] Pan, Y. P., Tian, S. L., Liu, D. W., Fang, Y. T., Zhu, X. Y., Zhang, Q., Zheng, B., Greg, M., \& Wang, Y. S. (2016). Fossil fuel combustion-related emissions dominate atmospheric ammonia sources during severe haze episodes: Evidence from ${ }^{15} \mathrm{~N}$-stable isotope in size-resolved aerosol ammonium. Environmental Science Technology, 50(15), 8049-8056. https://doi.org/10.1021/acs.est.6b00634

[10] Zheng, Y., Che, H. Z., Yang, L. K., Chen, J., Wang, Y. Q., Xia, X. G., Zhao, H, J., Wang, H., Wang, D. Y., Gui, K., An, L. C., Sun, T. Z., Yu, J., Kuang X., Li, X., Sun, E. W., Zhao, D. P.,Yang, D. S., Guo, T. L., \& Zhang, X. Y. (2017). Optical and radiative properties of aerosols during a severe haze episode over the North China Plain in December 2016. Journal of Meteorological Research, 31(6), 1045-1061. https://doi.org/10.1007/s13351-017-7073-7

[11] Beysens, D., Pruvost, V., \& Pruvost, B. (2016). Dew observed on cars as a proxy for quantitative measurements. Journal of Arid Environments, 135, 90-95. https://doi.org/10.1016/j.jaridenv.2016.08.014

[12] Zhu, Q. Q., Liu, G. R., Zheng, M. H., Zhang, X., Gao, L. R., Su, G. J., \& Liang, Y. (2018). Size distribution and sorption of polychlorinated biphenyls during haze episodes. Atmospheric Environment, 173, 38-45. https://doi.org/10.1016/j.atmosenv.2017.11.007

[13] An, J. L., Cao, Q. M., Zou, J. N., Wang, H. L., Duan, Q., Shi, Y. Z., Chen, C., \& Wang, J. X. (2018). Seasonal variation in water-soluble ions in airborne particulate deposition in the suburban Nanjing area, Yangtze River Delta, China, during haze days and normal days. Archives of Environmental Contamination and Toxicology, 74(1), 115. https://doi.org/10.1007/s00244-017-0447-0

[14] Lang, H. M., Qin, K., Yuan, L. M., Xiao, X., Hu, M. Y., Rao, L. L., \& Wang, L. Y. (2016). Particles size distributions and aerosol optical properties during haze-fog episodes in the winter of Xuzhou. China Environmental Science, 36(8), 2260-2269.

[15] Zhang, Q., Quan, J. N., Tie, X. X., Li, X., Liu, Q., Gao, Y., \& Zhao, D. L. (2015). Effects of meteorology and secondary particle formation on visibility during heavy haze events in Beijing, China. Science of the Total Environment, 502, 578-584. https://doi.org/10.1016/j.scitotenv.2014.09.079

[16] Beysens, D., Mongruel, A., \& Acker, K. (2017). Urban dew and rain in Paris, France: Occurrence and physico-chemical characteristic. Atmospheric Research, 189, 152-161. https://doi.org/10.1016/j.atmosres.2017.01.013

[17] Xu, Y. Y., Zhu, H., \& Tang, J. (2016). The effects of haze on dew quality in the urban ecosystem of Changchun, Jilin Province, China. Environmental Monitoring and Assessment, 188(2), article ID 02832. https://doi.org/10.1007/s10661-016-5131-8

[18] Xu, Y. Y. \& Zhu, X. Y. (2017). Recognizing dew as an indicator and an improver of near-surface air quality. Advances in Meteorology, 2017, article ID 3514743. https://doi.org/10.1155/2017/3514743

[19] Xu, Y. Y., Zhu, H., Sun, X. J., \& Meng, Q. L. (2017). A novel method for monitoring urban dew condensation and its application. Tehnički Vjesnik, 24(5), 1509-1515. https://doi.org/10.17559/TV-20170727025640 
[20] Bei, N. F., Xiao, B., Meng, N., \& Feng, T. (2016). Critical role of meteorological conditions in a persistent haze episode in the Guanzhong basin, China. Science of the Total Environment, 550, 273-284. https://doi.org/10.1016/j.scitotenv.2015.12.159

[21] Zhang, X. Y., Sun, J. Y., Wang, Y. Q., Li, W., Zhang, Q., Wang, W. G., Quan, J. N., Cao, G. L., Wang, J. Z., Yang, Y. Q., \& Zhang, Y. M. (2013). Factors contributing to haze and fog in China. Chinese Science Bulletin, 58, 1178-1187. https://doi.org/10.1360/972013-150

[22] Xu, Y. Y., Tang, J., Zhu, H., Lin, Y. Z., Jin, M. L., \& Zhu, X. Y. (2017). Monitoring dew condensation and its response to conventional meteorological factors in an urban ecosystem of northeastern China. Acta Ecologica Sinica (China), 37(7), 2382-2391. https:// doi.org/ 10.5846/stxb201601120074

[23] Richards, K. (2004). Observation and simulation of dew in rural and urban environments. Progress in Physical Geography, 28(1), 76-94. https://doi.org/10.1191/0309133304pp402ra

[24] Richards, K. (2005). Urban and rural dewfall, surface moisture, and associated canopy-level air temperature and humidity measurements for Vancouver, Canada. BoundaryLayer Meteorology, 114(1), 143-163. https://doi.org/10.1007/s10546-004-8947-7

[25] Ye, Y. H., Zhou, K., Song, L. Y., Jin, J. H., \& Peng, S. L. (2007). Dew amounts and its correlations with meteorological factors in urban landscapes of Guangzhou, China. Atmospheric Research, 86(1), 21-29. https://doi.org/10.1016/j.atmosres.2007.03.001

[26] Yan, B. X., Xu, Y. Y., \& Wang, L. X. (2010). Dew condensation rules in farmland ecosystem in Sanjiang Plain. Acta Ecologica Sinica (China), 30(20), 5577-5584. https://doi.org/10.1155/2015/793107

[27] Benlattar, M., Laatioui, S., Oualim, E. M., Mazroui, M., Mouhsen, A., \& Harmouchi, M. (2017). Numerical modelling of lawsonite thin film as radiative cooling minerals for dew harvesting. Results in Physics, 7, 19591964. https://doi.org/10.1016/j.rinp.2017.05.024

[28] Ernesto, A. T. J. \& Jasson, F. P. J. (2016). Winter dew harvest in Mexico City. Atmosphere, 7(1), 2-12. https://doi.org/10.3390/atmos7010002

[29] Xu, Y. Y., Yan, B. X., \& Tang, J. (2015). The effect of climate change on variations in dew amount in a paddy ecosystem of the Sanjiang Plain, China. Advances in Meteorology, 2015, article ID 793107. https:// doi.org/10.1155/2015/793107

[30] Zhu, Y. W., Liu, W. Q., Xie, P. H., Dou, K., Liu, S. S.,Si, F. Q., Li, S. W., \& Qin, M. (2009). Observational study of atmospheric HONO in the summer of Beijing. Environmental Science, 30(6), 1567-1573.

[31] An, J. L., Li, Y., Tang, Y. J., Chen, Y., \& Qu, Y. (2014) Advances in HONO sources, HONO simulations, and the impacts of the HONO sources on regional or global air quality. China Environmental Science, 34(2), 273-281.

[32] Wang, Y., Zhuang, G. S., Sun, Y. L., \& An, Z. S. (2006). The variation of characteristics and formation mechanisms of aerosols in dust, haze, and clear days in Beijing. Atmospheric Environment, 40(34), 6579-6591. https://doi.org/10.1016/j.atmosenv.2006.05.066

[33] Tan, J. H., Duan, J. C., He, K. B., Ma, Y. L., Duan, F. K., Chen, Y., \& Fu, J. M. (2009). Chemical characteristics of $\mathrm{PM}_{2.5}$ during a typical haze episode in Guangzhou. Journal of Environmental Sciences, 21(6), 774-781. https://doi.org/10.1016/S1001-0742(08)62340-2

[34] Yin, Z., Ye, X. N., Jiang, S. Q., Tao, Y., Shi, Y., Yang, X., \& Chen, J. M. (2015). Size-resolved effective density of urban aerosols in Shanghai. Atmospheric Environment, 100, 133-140. https://doi.org/10.1016/j.atmosenv.2014.10.055

\section{Contact information:}

Ying-ying XU, $\mathrm{PhD}$

1) Key Laboratory of Songliao Aquatic Environment, Ministry of Education, Jilin Jianzhu University, Room E414,

No. 5088 Xin Cheng Road, Changchun, 130118, Jilin Province, China

2) Chemistry Department, University of Toronto, Toronto, Ontario, Canada

E-mail: xuyingying.1019@aliyun.com

Hui ZHU, PhD, Associate Professor

(Corresponding author)

Key Laboratory of Wetland Ecology and Environment, Northeast Institute of Geography and Agroecology, Chinese Academy of Sciences, Room 405, No. 4888 Sheng Bei Road, Changchun, 130102, Jilin Province, China E-mail: zhuhui@iga.ac.cn

Yue-peng PAN, PhD, Associate Professor

State Key Laboratory of Atmospheric Boundary Layer Physics and Atmospheric Chemistry (LAPC), Institute of Atmospheric Physics, Chinese Academy of

Sciences, Room 306, Beijing 100029, China

E-mail: panyuepeng@mail.iap.ac.cn

\section{Jing XIE, Master}

Key Laboratory of Songliao Aquatic Environment, Ministry of Education, Jilin Jianzhu University, Room E304,

No. 5088 Xin Cheng Road, Changchun, 130118, Jilin Province, China

E-mail: 95839669@qq.com 